\title{
ANALISIS SISTEM INFORMASI MENGUKUR KEPUASAN PELAYANAN PELANGGAN DENGAN METODE SERVQUAL
}

\author{
${ }^{1}$ Satria \\ ${ }^{1)}$ Program Studi/Jurusan Sistem Informasi, STMIK Bani Saleh \\ email: satria1905@gmail.com
}

\begin{abstract}
PT Matahari Department Store Tbk is one company that stands in the fashion world. At this time in measuring customer satisfaction is still managed manually by using a piece of paper called VOC (Voice Of Customer). The data can be stored in the VOC map (Voice Of Customer) record can be stored in a different place. This results in not taking a while when making a subscription to follow up in improving service to customers. System design in measuring customer service to improve work efficiency and can be useful in helping work creativity and progress in services that are increased by the company takes precedence. The method that can be used to measure customer satisfaction is one of them is the servqual method. This method makes a comprehensive customer satisfaction assessment for services in the department store field. Assessment is carried out on the quality of 5 dimensions of service quality, namely: Tangibles or direct evidence, Reliability or reliability, Responsiveness or responsiveness, Assurance or guarantee, Emphaty or attention. Customer dissatisfaction arises because of the gap between customer expectations and the reality of service performance felt.
\end{abstract}

Keywords: Measurer, Service, Customer, Servqual

\begin{abstract}
ABSTRAK
PT Matahari Departemen Store Tbk adalah salah satu perusahaan yang berdiri dalam dunia fashion. Pada saat ini dalam mengukur kepuasan pelanggan masih dikelola secara manual dengan menggunakan selembar kertas yang disebut VOC (Voice of Customer). Data tersebut dapat disimpan di dalam rekapan map VOC (Voice of Customer) dapat disimpan pada tempat yang berbeda. Hal ini mengakibatkan membutuhkan waktu tidak sebentar pada saat melakukan penangganan untuk mentindak lanjutkan dalam meningkatkan pelayanan terhadap pelanggan. Perancangan sistem dalam mengukur pelayanan pelanggan untuk meningkatkan efisiensi kerja dan dapat bermanfaat dalam membantu kreaktifitas kerja dan kemajuan dalam pelayanan yang ditingkat oleh perusahaan lebih diutamakan. Adapun metode yang dapat digunakan untuk mengukur kepuasan pelanggan salah satunya adalah metode servqual. Metode ini membuat penilaian kepuasan pelanggan secara komprehenshif bagi pelayanan di bidang departemen store. Penilaian dilakukan terhadap mutu 5 dimensi mutu pelayanan yaitu: Tangibles atau bukti langsung, Reliability atau kehandalan, Responsiveness atau daya tanggap, Assurance atau jaminan, Emphaty atau perhatian. Ketidakpuasan pelanggan timbul karena terjadinya kesenjangan antara harapan pelanggan dengan kenyataan kinerja pelayanan yang rasakan.
\end{abstract}

Kata Kunci: Pengukur, Pelayanan, Pelanggan, Servqual 


\section{PENDAHULUAN}

\subsection{Latar Belakang Masalah}

PT Matahari Departemen Store Tbk adalah salah satu perusahaan yang berdiri dalam dunia fashion yang dijadikan objek penelitian oleh penulis. Pada saat ini data-data penelitian masih dikelola secara manual dengan menggunakan selembar kertas yang disebut VOC (Voice Of Customer). Data tersebut dapat disimpan di dalam rekapan map VOC (Voice Of Customer) dapat disimpan pada tempat yang berbeda. Hal ini mengakibatkan membutuhkan waktu tidak sebentar pada saat melakukan penanganan untuk mentindak lanjutkan meningkatkan pelayanan terhadap pelanggan.

Dalam model pencatatan seperti ini juga dapat mengakibatkan terjadinya kehilangan kertas VOC (Voice Of Customer) baik sengaja maupun tidak sengaja. Disamping itu pengelolah data penelitian seperti ini juga dapat mengakibatkan integritas dan keamanan kertas VOC (Voice Of Customer) yang tdak terjamin. Disini pegelolah data secara komputerisasi dengan sebuah program aplikasi khusus sangat diperlukan untuk mendukung sebuah sistem informasi yang cepat dan akurat, sehinggan permasalahan waktu dan tingkat validitas data penelitian dan dapat ditekan seminimal mungkin.

Permasalahan lain yang sering muncul seain keterlambatan adalah kesalahan informasi berkaitan dengan identitas pelanggan, jumlah pelanggan yang telah melakukan komplen (keluhan). Hal ini muncul karena pencatatan data masih bersifat manual dan data tidak tersimpan secara benar dan tidak terjamin dengan baik.

Oleh karena itu apabila ada pelanggan yang mengeluh atau memberikan suatu nilai kepuasannya hal ini mejadi momentum yang baik karena memberikan kesempatan kepada perusahaan untuk memulihkan jasa pelanggan yang mengeluh dapat menjadi pelanggan yang loyal apabila perusahaan dapat menangani keluhan perusahaan tersebut dengan baik. Adapun metode yang dapat digunakan untuk mengukur kepuasan pelanggan salah satunya adalah metode servqual.Metode ini membuat penilaian kepuasan pelanggan secara komprehenshif bagi pelayanan di bidang departemen store. Penilaian dilakukan terhadap mutu 5 dimensi mutu pelayanan yaitu: Tangibles atau bukti langsung, Reliability atau kehandalan, Responsiveness atau daya tanggap, Assurance atau jaminan, Emphaty atau perhatian. Ketidakpuasan pelanggan timbul karena terjadinya kesenjangan antara harapan pelanggan dengan kenyataan kinerja pelayanan yang dirasakannya ( Mohammad Imam Shalahudin, : 2011).

\subsection{Tujuan Penelitian}

Tujuan dari pembuatan sistem informasi pengukuran pelayanan pelanggan adalah:

a) PT Matahari Departemen Store dapat memanfaatkan aplikasi rancangan bangunan aplikasi dalam mengukur pelayanan pelanggan untuk meningkatkan efisiensi kerja dan dapat bermanfaat dalam membantu kreaktifitas kerja dan kemajuan dalam pelayanan yang di tingkat oleh perusahaan lebih diutamakan.

b) Mengidentifikasi faktor-faktor apa saja yang menjadi penghambat dalam optimalisasi pelayanan Sistem Informasi dalam pelanggan pada PT Matahari Departemen Store Blu Plaza Bekasi.

c) Menganalisa sistem Informasi yang digunakan dalam rencana pengembangan sistem informasi pada PT Matahari Departemen Store Blu Plaza Bekasi dalam rangka optimalisasi mengukur pelayanan pelayanan.

\section{METODOLOGI PENELITIAN}

\subsection{Metode Waterfall}

Menurut Rossa dan M. Shalahuddin menyimpulkan bahwa model SDLC air terjun (waterfall) sering juga disebut model sekuensial linier (sequential linear) atau alur hidup klasik (klasik lifecycle).Model air terjun menyediakan pendekatan alur hidup perangkat lunak secara sekuensial atau terurut dimulai dari analisis, desain, pengodean, pengujian, dan tahap pendukung (support). Berikut adalah gambar model air terjun: 


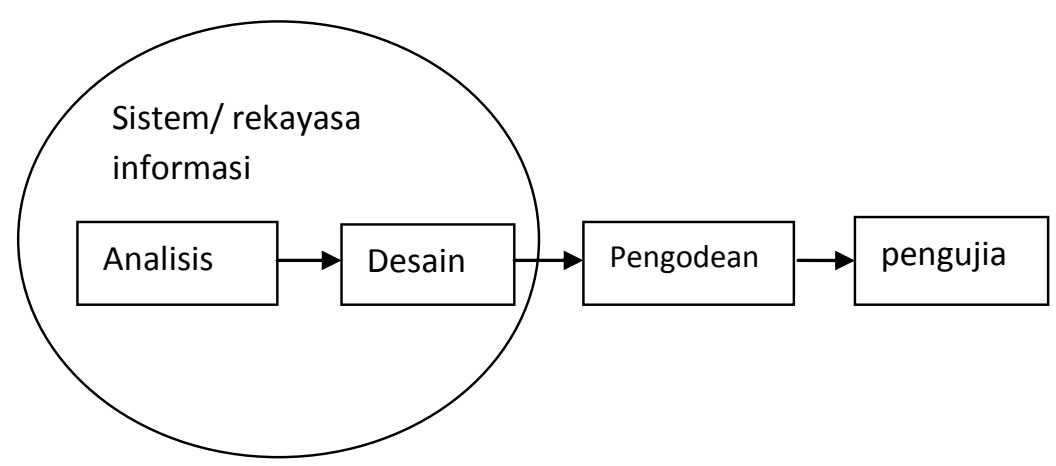

Sumber: Rosa A. S dan M. Shalahuddin, 2014:29

Gambar 1 Ilustrasi model waterfall

A. Analisis kebutuhan perangkat lunak

Proses pengumpulan kebutuhan dilakukan secara intensif untuk menspesifikasikan kebutuhan perangkat lunak agar untuk dapat dipahami perangkat lunak seperti apa yang dibutuhkan oleh user. Spesifikasi kebutuhan perangkat lunak pada tahap ini perlu untuk didokumentasikan.

B. Desain

Desain perangakat lunak adalah proses multi langkah yang fokus pada desain pembuatan program perangakat lunak termasuk struktur data, arsitektur perangkat lunak, representasi antar muka, dan prosedur pengodean. Tahap ini mentranlasi kebutuhan ke representasi desain agar dapat diimplementasikan menjadi program pada tahap selanjutnya.Desain perangkat lunak yang dihasilkan pada tahap ini juga perlu didokumentasikan.

C. Pembuatan kode program

Desain harus ditranslasikan ke dalam program perangkat lunak.Hasil dari tahap ini adalah program komputer sesuai dengan yang telah dibuat pada tahap desain.

D. Pengujian

Pengujian fokus pada perangkat lunak secara dari segi lojik dan fungsional dan memastikan bahwa semua bagian sudah diuji.Hal ini dilakukan untuk meminimalisir kesalahan (error) dan memastikan keluaran yang dihasilkan sesuai dengan yang diinginkan.

E. Pendukung (support) atau pemeliharaan (maintenance)

Tidak menutup kemungkinan sebuah perangkat lunak mengalami perubahan ketika sudah dikirimkan ke user.Perubahan bisa terjadi karena adanya kesalahan yang muncul dan tidak terdeteksi saat pengujian atau perangkat lunak harus beradaptasi dengan lingkungan baru. Tahap pendukung atau pemeliharaan dapat mengulangi proses pengembangan mulai dari analisis spesifikasi untuk perubahan perangkat lunak yang sudah ada, tapi tidak untuk membuat perangkat lunak yang baru.

Dari kenyataan yang terjadi sangat jarang model air terjun dapat dilakukan sesuai alurnya karena sebab berikut:

a. Perubahan spesifikasi perangkat lunak yang terjadi ditengah alur pengembangan.

b. Sangat sulit bagi pelanggan untuk mendefinisikan semua spesifikasi di awal alur pengembangan. Pelanggan sering kali butuh contoh (prototype) untuk menjabarkan spesifikasi kebutuhan sistem lebih lanjut.

c. Pelanggan tidak mungkin bersabar mengakomodasikan perubahan yang diperlukan di akhir alur pengembangan.

Dengan berbagai kelemahan yang dimiliki model air terjun tapi model ini telah menjadi model dasar dari model-model lain dalam melakukan perbaikan model pengembangan perangkat lunak.Model air terjun ini sangat cocok digunakan kebutuhan pelanggan sudah dapat dipahami dan kemungkinan terjadinya perubahan kebutuhan selama pengembangan perangkat lunak kecil.Hal positif dari model air terjun adalah struktur tahap pengembangan sistem jelas, dokumentasi 
dihasilkan disetiap tahap sebelumnya selesai dijalankan (tidak ada tupang tindih pelaksanaan tahap).

\subsection{Pengertian Servqual}

Metode servqual merupakan metode yang digunakan untuk mengukur kualitas layanan dari atribut masing-masing dimensi, sehingga akan diperoleh nilai gap (kesenjangan) yang merupakan selisih antara persepi responden terhadap yang akan diterima, sihingga akan diperoleh nilai gap yang merupakan selisih antara responden terhadap layanan yang diterima dengan kenyataan respden terhadap layanan yang akan diterima.

Metode servqual memiliki dua perspektif internal dan prespektif eksternal. Perspektif eksternal digunakan untuk memahami apa yang diharapkan responden, dirasakan responden dan kepuasan responden. Pengukuran menggunakan servqual adalah suatu peralatan mengukur kualitas dari pelayanan. Sedangkan perspektif interal diidentifikasikan dengan bebas kesalahan dan melakukan dengan benar saat pertama kali serta menyesuaikan dengan permintaan (Erlina : 2011).

Ada lima komponen utama kualitas layanan yakni reliability (reliabilitas), assurance (kepastian), tangible (nyata), empathy (empati) dan responsiveness (daya tanggap). Komponen dapat diingat dengan singkatan RATER, seperti di bawah ini Yosi Yonata, Cut Fiarni, Marseli Afyuni Tania (2016:14) :

a. Reliability (Reliabilitas)

Kemampuan untuk menjalankan layanan yang dijanjikan secara akurat dan dapat diandalkan.

b. Assurance (Jaminan)

Pengetahuan dan kesopanan pegawai dan kemampuan mereka memberika kepercayaan dan keyakinan.

c. Tangible (Bukti Fisik)

Tampilan fasilitas fisik, perlengkapan, personel, dan materi komunikasi.

d. Empathy (Empati)

Pengungkapan perhatian dan kepedulian kepada pelanggan.

e. Responsiveness (Daya Tanggap)

Kemauan untuk membantu pelanggan dan memberikan layanan dengan segera.

Pengukuran kualitas jasa dalam model servqual ini didasarkan pada skala multiitem yang dirancang untuk mengukur harapan dan persepsi responden. Serta Gap diantar keduanya pada lima dimensi kualitas jasa yaitu (tangible, reliability, responsiveness, assurance dan empathy), kelima dimensi kualitas tersebut dijabarkan dalam beberapa butir pertanyaan untuk atribut harapan dan variable persepsi berdasarkan skala likert.(Dede Insan Nurdiansyah $2014: 601$ )

Skor servqual untuk tiap pasang pertayaan bagi masing-masing pelanggan dapat di hitung berdasarkan rumus berikut:

a. Penghitungan harapan responden mengenai pelayanan :

$\sum \mathrm{Yi}=\left(\sum \mathrm{ST} \times 1\right)+\left(\sum \mathrm{T} \times 2\right)+\left(\sum \mathrm{CT} \times 3\right)+\left(\sum \mathrm{TT} \times 4\right)+$

$\left(\sum \mathrm{STT} \times 5\right)$.

Keterangan :

$\sum \mathrm{Yi}=$ Jumlah bobot jawaban pernyataan harapan variable ke- $\mathrm{i}$

$\sum \mathrm{ST} \quad=$ Jumlah orang yang memilih jawaban sangat terpenuhi

$\sum \mathrm{T}=$ Jumlah orang yang memilih jawaban terpenuhi

$\sum \mathrm{CT}=$ Jumlah orang yang memilih jawaban cukup terpenuhi

$\sum \mathrm{TT}=$ Jumlah orang yang memilih jawaban tidak terpenuhi

$\sum$ STT = Jumlah orang yang memilih jawaban sangat tidak terpenuhi

$1,2,3,4,5=$ Skor untuk skala Likert

b. Perhitungan kenyataan responden mengenai pelayanan :

$\sum \mathrm{Xi}=\left(\sum \mathrm{ST} \times 1\right)+\left(\sum \mathrm{T} \times 2\right)+\left(\sum \mathrm{CT} \times 3\right)+\left(\sum \mathrm{TT} \times 4\right)$

$+\left(\sum \mathrm{STT} \times 5\right)$ 
Keterangan :

$\sum \mathrm{Xi}=$ Jumlah bobot jawaban pernyataan harapan variable ke-i

$\sum$ ST = Jumlah orang yang memilih jawaban sangat terpenuhi

$\sum \mathrm{T}=$ Jumlah orang yang memilih jawaban terpenuhi

$\sum \mathrm{CT}=$ Jumlah orang yang memilih jawaban cukup terpenuhi

$\sum \mathrm{TT}=$ Jumlah orang yang memilih jawaban tidak terpenuhi

$\sum$ STT = Jumlah orang yang memilih jawaban sangat tidak terpenuhi

$\sum$ STT $=$ Jumlah orang yang memilih jawaban sangat tidak terpenuhi

$1,2,3,4,5=$ skor untuk skala Likert

c. Rata - rata jawaban responden pada pernyataan harapan dapat dihitung dengan persamaan :

Keterangan :

$$
\mathrm{Yi}=\frac{\sum \mathrm{Yi}}{\mathrm{n}}
$$

$\mathrm{Yi}=\mathrm{Rata}-$ rata jawaban responden untuk pernyataan harapan

$\sum \mathrm{Yi}=$ Jumlah bobot jawaban pernyataan harapan atribut ke-i

$\mathrm{n} \quad=$ Jumlah responden

d. Rata - rata jawaban responden pada pernyataan kenyataan dapat dihitung dengan persamaan :

Keterangan :

$$
\mathrm{Xi}=\frac{\sum \mathrm{Xi}}{\mathrm{n}}
$$

$\mathrm{Xi}=$ Rata - rata jawaban responden untuk pernyataan kenyataan

$\sum \mathrm{Xi}=$ Jumlah bobot jawaban pernyataan kenyataan atribut ke-i

$\mathrm{n} \quad=$ Jumlah responden

e. Nilai Gap 5 dimensi servqual adalah nilai kesenjangan yang terjadi antara harapan dan kenyataan pengguna jasa yang diperoleh dari pernyataan kualitas pelayanan jasa tentang harapn responden terhadap pelayanana yang ingin dirasakan dan nilai rata - rata kenyataan pelayanan yang dirasakan responden pada kondisi yang sebenarnya. Untuk mengetahui nilai gap tersebut persamaan berikut:

Keterangan:

$$
\mathrm{SQ}_{\mathrm{i}}=\mathrm{X}_{\mathrm{i}}-Y_{i}
$$

$\mathrm{SQ}_{\mathrm{i}} \quad=$ Nilai gap attribute $\mathrm{ke}-\mathrm{i}$

$\mathrm{X}_{\mathrm{i}} \quad=$ NIlai rata-rata kenyataan attribute ke $-\mathrm{i}$

$\mathrm{Y}_{\mathrm{i}} \quad=$ Nilai rata-rata harapan attribute $\mathrm{ke}-\mathrm{i}$

\section{HASIL DAN ANALISA}

\subsection{Analisa Sistem yang Berjalan}

Sistem saat ini yang sedang berjalan di PT Matahari Blu Plaza adalah sebagai berikut:

a. Pelanggan yang kurang puas untuk dilayani oleh pegawai matahari hendak mendatangi tempat Customer Service untuk mengungkapkan keluhan pelanggan, tentang apa yang pelanggan rasakan oleh pegawai matahari serta mengisi from keluhan yang diberikan oleh CustomerService.

b. Data keluhan pelanggan setelah itu diberikan kepada petugas Customer Service.

c. Data form keluhan setelah itu di arsip kan oleh customer service ke dalam map dan di kelompokan berdasarkan bulan.

\section{Kelemahan Sistem Berjalan}

Berdasarkan analisa sistem berjalan di atas maka di dapatkan juga kelemahan sistem berjalan sebagai berikut : 
a. Pengumpulan data ini masih dalam sistem manual hal ini menimbulkan resiko penumpukan data from keluhan.

b. Pengumpulan data yang telah dikumpulkan dan telah diarsipkan menimbulkan resiko dalam penyimpanan, resiko hilangnya data dan rusaknya data.

c. Data yang tersimpan secara fisik akan menimbulkan resiko dalam kesulitan ketika mencari data keluhan pelanggan

Untuk mengetahui alur aktivitas yang berjalan, maka akan di tunjukkan pada diagram berjalan sebagai berikut :

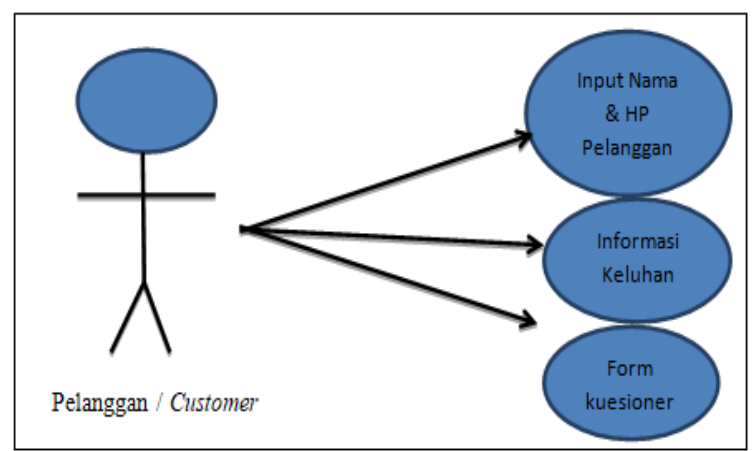

Gambar 2 Use Case Sedang Berjalan

\subsection{Sistem yang diusulkan pada PT. Astrido Jaya Mobilindo}

Ketika mendapatkan keluhan dari pelanggan seharusnya diterima sebagai suatu hadiah yang diberikan pelanggan untuk perusahaan. Dengan adanya keluhan maka perusahaan dapat terus melakukan perbaikkan terhadap pelayanan yang diberikan. Besar atau kecilnya suatu keluhan apabila tidak dikelolah dengan cepat dan baik akan berdampak kepada citra perusahaan itu sendiri.

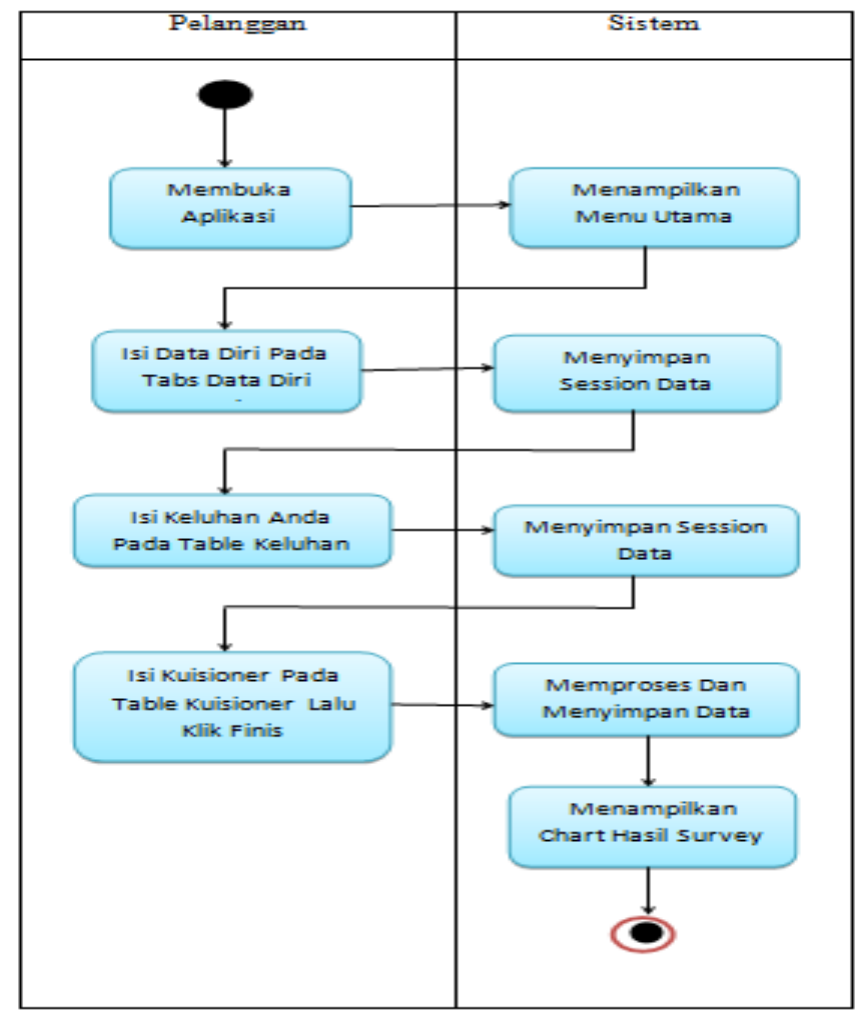

Gambar 3 Kerangka Sistem yang diusulkan 


\subsection{Kelebihan Sistem Yang Diusulkan}

a. Memberikan kemudahan kepada pelanggan dalam memperoleh informasi keluhan dengan mengakses aplikasi WEBbrowser perusahaan dengan menggunakan handphone maupun personal computer yang berhubungan dengan internet.

b. Memberikan kemudahan bagi customer service untuk mengakses dan menginformasikan keluhan pelanggan yang langsung diterima atau diperoses oleh unit terkait.

Berikut ini adaah contoh perhitungan Gap dari kuisioner pada Sistem Kepuasan Pelanggan PT Matahari Departem Store:

Tabel 1 Tabel Hasil Survey dari 30 Pelanggan

\begin{tabular}{|c|c|c|c|c|c|c|}
\hline \multirow{2}{*}{ No } & \multirow{2}{*}{ Kuisioner } & \multicolumn{5}{|c|}{ Bobot } \\
\hline & & SP & $\mathrm{P}$ & $\mathrm{CP}$ & $\mathrm{TP}$ & STP \\
\hline 1. & $\begin{array}{l}\text { Bagaimana keramahan karyawan kami } \\
\text { dalam melayani anda selama berbelanja? }\end{array}$ & 2 & 15 & 3 & 5 & 5 \\
\hline 2. & $\begin{array}{l}\text { Bagaimana kesiapan karyawan kami } \\
\text { dalam melayani anda selama berbelanja? }\end{array}$ & 5 & 10 & 5 & 5 & 5 \\
\hline 3. & $\begin{array}{l}\text { Bagaimana kecepatan karyawan kami } \\
\text { dalam melayani anda selama berbelanja? }\end{array}$ & 10 & 5 & 5 & 5 & 5 \\
\hline 4. & $\begin{array}{l}\text { Bagaimana pengetahuan karyawan kami } \\
\text { tentang produk-produk matahari? }\end{array}$ & 5 & 15 & 5 & 2 & 3 \\
\hline 5. & Bagaimana penampilan karyawan kami? & 10 & 10 & 5 & 2 & 3 \\
\hline 6. & $\begin{array}{l}\text { Bagaimana kualitas barang yang kami } \\
\text { jual? }\end{array}$ & 8 & 12 & 5 & 5 & 5 \\
\hline 7. & $\begin{array}{l}\text { Bagaimana dengan kelengkapan produk } \\
\text { yang kami jual? }\end{array}$ & 7 & 8 & 10 & 3 & 2 \\
\hline 8. & $\begin{array}{l}\text { Bagaimana dengan kenyamanan toko } \\
\text { kami selama anda berbelanja? }\end{array}$ & 10 & 10 & 2 & 4 & 4 \\
\hline 9. & Bagaimana kebersihan toko kami? & 5 & 10 & 5 & 5 & 5 \\
\hline 10. & Bagaimana kerapihan toko kami? & 5 & 12 & 4 & 4 & 5 \\
\hline
\end{tabular}

Keterangan :

SP : Sangat Baik

$\mathrm{P} \quad$ : Baik

CP : Cukup Baik

TP : Tidak Baik

STP : Sangat Tidak Baik

10,5,2 : Jumlah Pelanggan

Dari Tabel 3.5 diatas dapat dilakukan perhitungan Gap dengan menghitung jumlah bobot penyataan kenyataan variable ke -i dengan menggunakan rumus :

$\sum \mathrm{Xi}=\left(\sum \mathrm{SP} \times 1\right)+\left(\sum \mathrm{P} \times 2\right)+\left(\sum \mathrm{CP} \times 3\right)+\left(\sum \mathrm{TP} \times 4\right)+\left(\sum \mathrm{STP} \times 5\right)$

Keterangan :

$\sum \mathrm{Xi}=$ Jumlah bobot jawaban pernyataan harapan variable ke-i

$\sum \mathrm{ST}=$ Jumlah orang yang memilih jawaban sangat baik

$\sum \mathrm{T}=$ Jumlah orang yang memilih jawaban baik

$\sum \mathrm{CT}=$ Jumlah orang yang memilih jawaban cukup baik

$\sum \mathrm{TT}=$ Jumlah orang yang memilih jawaban tidak baik

$\sum$ STT $=$ Jumlah orang yang memilih jawaban sangat tidak baik

$1,2,3,4,5=$ skor untuk skala Likert 
Dengan menggunkan rumus diatas maka di dapatkan hasil sebagai berikut:

Tabel 2 Hasil Perhitungan Bobot

\begin{tabular}{|c|c|c|}
\hline \multirow[b]{2}{*}{ No } & \multirow[b]{2}{*}{ Attribut } & Bobot \\
\hline & & $\sum \mathbf{X i}=\left(\sum \mathbf{S P} \times \mathbf{1}\right)+\left(\sum \mathbf{P} \times \mathbf{2}\right)+\left(\sum \mathbf{C P} \times \mathbf{3}\right)+\left(\sum \mathbf{T P} \times \mathbf{4}\right)+\left(\sum \mathbf{S T P} \times \mathbf{5}\right)$ \\
\hline 1. & $\mathrm{~K} 1$ & 86 \\
\hline 2. & $\mathrm{~K} 2$ & 65 \\
\hline 3. & K3 & 80 \\
\hline 4. & K4 & 73 \\
\hline 5. & K5 & 68 \\
\hline 6. & K6 & 92 \\
\hline 7. & K7 & 75 \\
\hline 8. & K8 & 72 \\
\hline 9. & K9 & 85 \\
\hline 10. & K10 & 82 \\
\hline
\end{tabular}

Keterangan :

K1 : Kuisioner ( pertanyaan pertama atau nomer 1 )

SP : Sangat Baik

$\mathrm{P} \quad$ : Baik

CP : Cukup Baik

TP : Tidak Baik

STP : Sangat Tidak Baik

Bobot : Hasil dari perhitungan perorangan yang memilih SP,P atau STP

Dari Tabel 3.6 diatas dapat dilakukan perhitungan Gap dengan menghitung jumlah bobot penyataan kenyataan variable ke -i dengan menggunakan rumus :

$\sum \mathrm{Xi}=\left(\sum \mathrm{SB} \times 1\right)+\left(\sum \mathrm{B} \times 2\right)+\left(\sum \mathrm{CB} \times 3\right)+\left(\sum \mathrm{TB} \times 4\right)+\left(\sum \mathrm{STb} \times 5\right)$

Keterangan :

$\sum \mathrm{Xi}=$ Jumlah bobot jawaban pernyataan harapan variable ke-i

$\sum \mathrm{ST}=$ Jumlah orang yang memilih jawaban sangat baik

$\sum \mathrm{T}=$ Jumlah orang yang memilih jawaban baik

$\sum \mathrm{CT}=$ Jumlah orang yang memilih jawaban cukup baik

$\sum \mathrm{TT}=$ Jumlah orang yang memilih jawaban tidak baik

$\sum$ STT $=$ Jumlah orang yang memilih jawaban sangat tidak baik

$1,2,3,4,5=$ skor untuk skala Likert.

Tabel 3 Hasil Nilai Rata-Rata Kuisioner dengan 30 Pelanggan

\begin{tabular}{|c|c|c|c|}
\hline No. & Attribute & Bobot & Rata - Rata \\
\hline 1. & K1 & 86 & 2.86 \\
\hline 2. & K2 & 65 & 2.16 \\
\hline 3. & K3 & 80 & 2.66 \\
\hline 4. & K4 & 73 & 2.43 \\
\hline 5. & K5 & 68 & 2.26 \\
\hline 6. & K6 & 92 & 3.06 \\
\hline 7. & K7 & 75 & 2.50 \\
\hline 8. & K8 & 72 & 2.40 \\
\hline 9. & K9 & 85 & 2.83 \\
\hline 10. & K10 & 82 & 2.73 \\
\hline
\end{tabular}


Keterangan :

K1 : Kuisioner ( pertanyaan pertama atau nomer 1)

Bobot : Hasil dari perhitungan perorangan yang memilih SB,B atau STB

Rata - Rata : Jumlah persenan di dapat dari perhitungan nilai Bobot di bagi Jumlah 30 pelanggan yang memilih kuisioner kepuasan.

Dari table 3 dapat di hitung nilai rata - rata jawaban responden pada pernyataan harapan dapat dihitung dengan persamaan :

Keterangan :

$$
\mathrm{Yi}=\frac{\sum \mathrm{Yi}}{\mathrm{n}}
$$

$\mathrm{Yi}=\mathrm{Rata}-$ rata jawaban responden untuk pernyataan harapan

$\sum \mathrm{Yi}=$ Jumlah bobot jawaban pernyataan harapan atribut ke-i

$\mathrm{n} \quad=$ Jumlah responden

Tabel 4 Hasil Nilai Rata - Rata Kuisioner Servqual

\begin{tabular}{|c|c|c|c|c|c|c|}
\hline \multirow{2}{*}{ No. } & \multirow{2}{*}{ Attribut } & \multicolumn{2}{|c|}{ Harapan } & \multicolumn{2}{c|}{ Kenyataan } & \multirow{2}{*}{ Gap } \\
\cline { 3 - 6 } & Bobot & Rata & Bobot & Rata & \\
\hline 1. & K1 & 60 & 2.00 & 86 & 2.86 & $\mathbf{0 . 8 6}$ \\
\hline 2. & K2 & 60 & 2.00 & 65 & 2.16 & $\mathbf{0 . 1 6}$ \\
\hline 3. & K3 & 60 & 2.00 & 80 & 2.66 & $\mathbf{0 . 6 6}$ \\
\hline 4. & K4 & 60 & 2.00 & 73 & 2.43 & $\mathbf{0 . 4 3}$ \\
\hline 5. & K5 & 60 & 2.00 & 68 & 2.26 & $\mathbf{0 . 2 6}$ \\
\hline 6. & K6 & 60 & 2.00 & 92 & 3.06 & $\mathbf{1 . 0 6}$ \\
\hline 7. & K7 & 60 & 2.00 & 75 & 2.50 & $\mathbf{0 . 5 0}$ \\
\hline 8. & K8 & 60 & 2.00 & 72 & 2.40 & $\mathbf{0 . 4 0}$ \\
\hline 9. & K9 & 60 & 2.00 & 85 & 2.83 & $\mathbf{0 . 8 3}$ \\
\hline 10. & K10 & 60 & 2.00 & 82 & 2.73 & $\mathbf{0 . 7 3}$ \\
\hline
\end{tabular}

Keterangan :

K1 : Kuisioner ( pertanyaan pertama atau nomer 1)

Harapan : Nilai bobot dan rata adalah suatu nilai harapan yang perusaha inginkan

Kenyataan : Nilai bobot dan rata adalah nilai kenyataan yang pelanggan merasakan kepuasan terhaap pelayanan pelanggan

Gap : Jumlah gap di dapat dari nilai rata harapan dikurang nilai rata kenyataan

Dari table 4 dapat di hitung rata - rata jawaban responden pada pernyataan kenyataan dapat dihitung dengan persamaan :

Keterangan :

$$
\mathrm{Xi}=\frac{\sum \mathrm{Xi}}{\mathrm{n}}
$$

$\mathrm{Xi}=\mathrm{Rata}-$ rata jawaban responden untuk pernyataan kenyataan

$\sum \mathrm{Xi}=$ Jumlah bobot jawaban pernyataan kenyataan atribut ke-i

$\mathrm{n} \quad=$ Jumlah responden

\section{Kesimpulan :}

Pada gambar diatas,menjelaskan bahwa hasil nilai rata-rata kuisioner servqual mempunya nilai harapan pelayanan sehingga mempunyai batasan tolak ukur untuk meningkatkan pelayanan perusahaan. Setiap nilai rata-rata kuisioner juga mempunyai nilai kenyaatanan sehingga dapat dibuktikan pelayanan apa saja yang kurang untuk pelanggan. Perhitungan nilai gab di dapat dari nilai harapan rata-rata dibagi nilai kenyataan rata-rata sehingga dapatlah nilai gap pada kuisioner servqual dan nilai gap bisa dilihat dari hasil pertanyaan kuisioner yang harus ditinggatkan seperti gambra diatas bahwa pertanyaan K6 ( Bagaimana kualitas barang yang di jual ) medapatka nilai 
gap 1,06 yang menjelaskan bahwa rentang nilai gapnya terdapat $>1,00 \mathrm{~s} / \mathrm{d}<2,00$ yaitu harus di optimalkan untuk kualitas barang yang di jualnya. Dari gambar diatas menjelaskan bahwa dari 30 pelanggan yang mengisi kuisioner merasa tidak puas atas kualitas barang yang di jual sehingga perusahaan harus mengoptimalkan untuk kualitas barang yang dijual oleh perusahaan.

Tabel 5. Rentang Nilai Gap

\begin{tabular}{|c|c|}
\hline$<0 \mathrm{~s} / \mathrm{d}<1.00$ & Sangat Memenuhi \\
\hline$>1.00 \mathrm{~s} / \mathrm{d}<2.00$ & Optimalkan \\
\hline$>2.00 \mathrm{~s} / \mathrm{d}<3.00$ & Tingkatkan \\
\hline$>3.00 \mathrm{~s} / \mathrm{d}<4.00$ & Perbaiki \\
\hline$>4.00$ & Lebih Diperbaiki \\
\hline
\end{tabular}

Keterangan :

$<0 \mathrm{~s} / \mathrm{d}<1.00 \quad: \quad$ Sangat memenuhi (pelanggan sangat puas dengan pelayanan)

$>1.00 \mathrm{~s} / \mathrm{d}<2.00$ : Optimalkan (pelayanan harus di tambahkan lagi)

$>2.00 \mathrm{~s} / \mathrm{d}<3.00$ : Tingkatkan (pelanggan merasa kurang sehingga harus lebih baik lagi untuk melayani pelanggan)

$>3.00 \mathrm{~s} / \mathrm{d}<4.00$ : $\quad$ Perbaiki (pelayanan kurang sehinggan banyak yang harus di perbaiki)

$>4.00 \quad: \quad$ lebih diperbaiki (pelayanan yang di berikan sanganlah kurang sehingga harus lebih di perhatikan dan di perbaiki lagi).

Dari table 5 dapat diperoleh dari pernyataan kualitas pelayanan jasa tentang harapan responden terhadap pelayanana yang ingin dirasakan dan nilai rata - rata kenyataan pelayanan yang dirasakan responden pada kondisi yang sebenarnya.

\subsection{IMPLEMENTASI SISTEM}

Menu Login

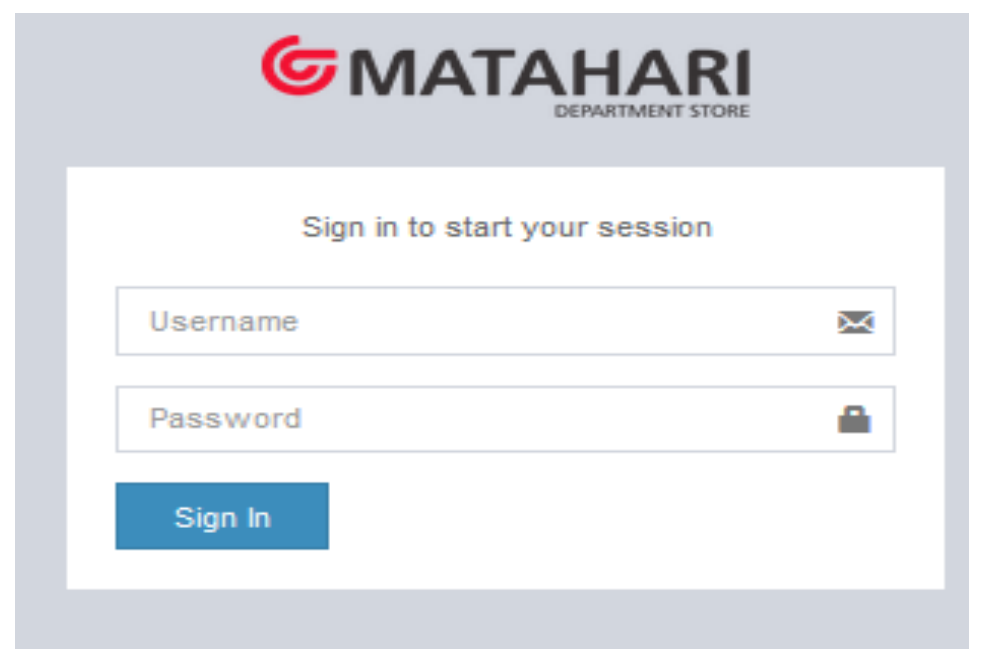

Gambar 4 Menu Login 
Menu Utama

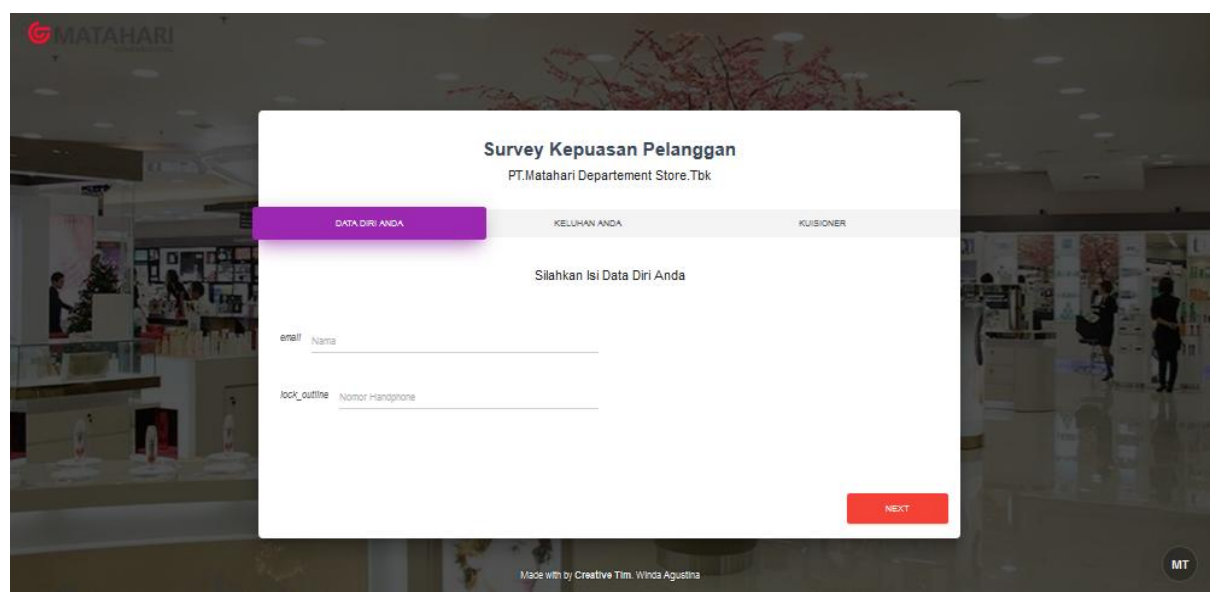

Gambar 5 Menu Utama

Form Data Diri

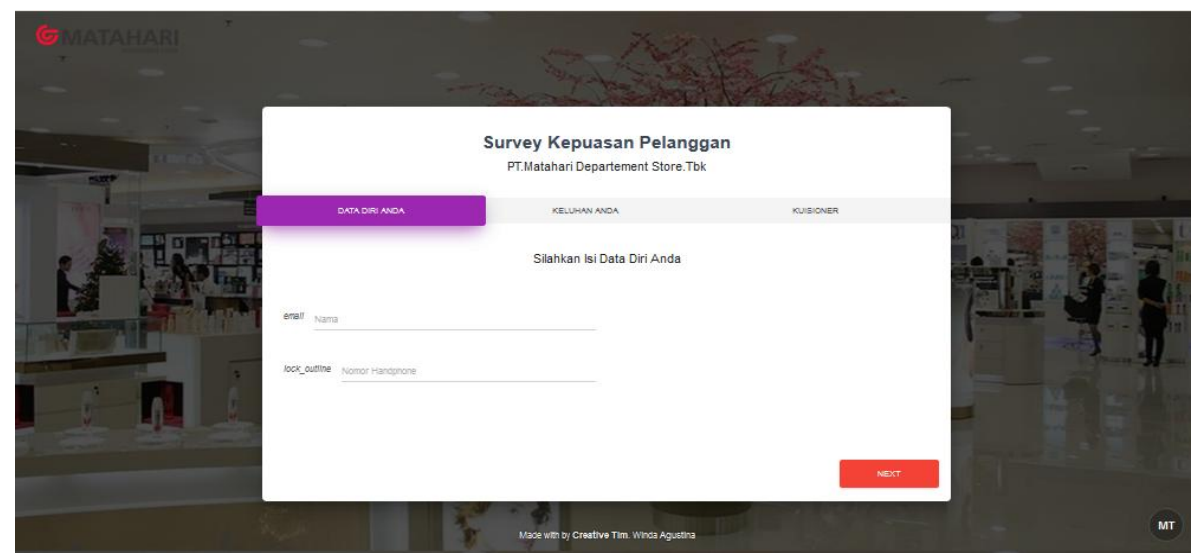

Gambar 6 Form Data Diri

Form Keluhan

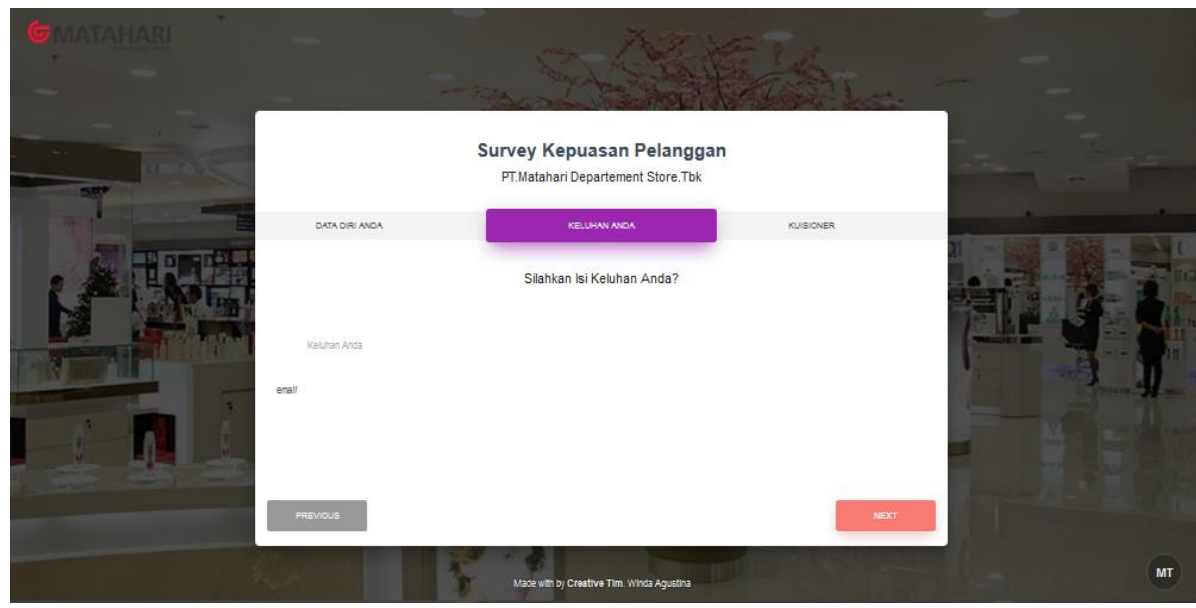

Gambar 7 Form Data Keluhan 
Form Kuisioner

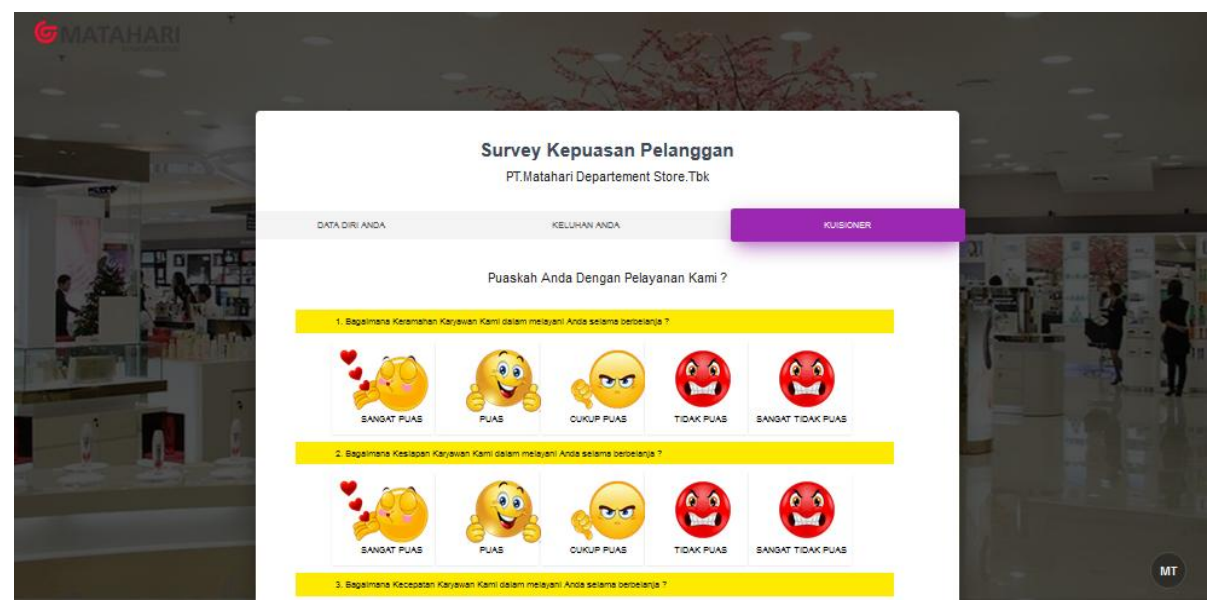

Gambar 8 Form Kuisioner

Presentasi

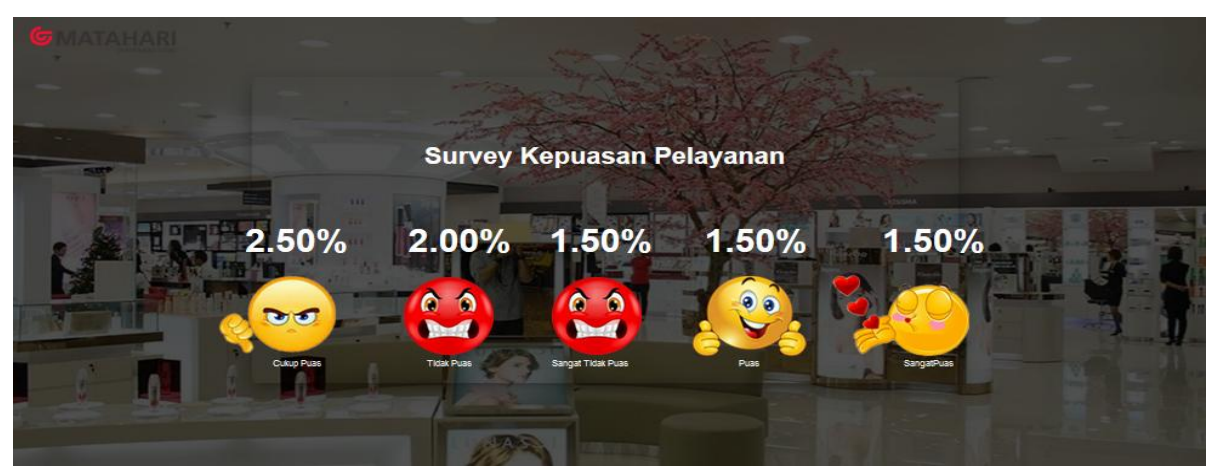

Gambar 9 Presentasi

Laporan Gap

Tabel 6 Laporan Gap Dari Masing-Masing Kuisioner

\begin{tabular}{|c|l|c|}
\hline No & \multicolumn{1}{|c|}{ Kuisioner } & Gap \\
\hline 1. & $\begin{array}{l}\text { Bagaimana keramahan karyawan kami dalam melayani anda selama } \\
\text { berbelanja? }\end{array}$ & 0,86 \\
\hline 2. & $\begin{array}{l}\text { Bagaimana kesiapan karyawan kami dalam melayani anda selama } \\
\text { berbelanja? }\end{array}$ & 0.16 \\
\hline 3. & $\begin{array}{l}\text { Bagaimana kecepatan karyawan kami dalam melayani anda selama } \\
\text { berbelanja? }\end{array}$ & 0.66 \\
\hline 4. & Bagaimana pengetahuan karyawan kami tentang produk-produk matahari? & 0.43 \\
\hline 5. & Bagaimana penampilan karyawan kami? & 0.26 \\
\hline 6. & Bagaimana kualitas barang yang kami jual? & 1.06 \\
\hline 7. & Bagaimana dengan kelengkapan produk yang kami jual? & 0.50 \\
\hline
\end{tabular}




\begin{tabular}{|c|l|c|}
\hline 8. & Bagaimana dengan kenyamanan toko kami selama anda berbelanja? & 0.40 \\
\hline 9. & Bagaimana kebersihan toko kami? & 0.83 \\
\hline 10. & Bagaimana kerapihan toko kami? & 0.73 \\
\hline
\end{tabular}

Dari gambar diatas, pada data ini menjelaskan hasil laporan gap dari 30 pelanggan yang mengisi kuisioner, penilaianyang diberikan oleh pelanggan dari masing-masing kuisioner terhadap pelayanan dan area perusahaan PT Matahari Departemen Store, sehingga perusahan dapat meninggkatkan kualitas pelayanan dan area perusahan agar lebih baik lagi sehingga pelanggan merasa puas untuk bisa datang kembali ke PT Matahari Departemen Store.

\section{KESIMPULAN DAN SARAN}

\subsection{Kesimpulan}

1. Dengan menggunakan rancang bangun ini dapat memudahkan karyawan, Customer Service, Supervisor Customer Service dan Menejemen dalam menangani kekurangan pelayanan dan area perusahaan yang harus ditingkatkan sehingga perusahaan dapat meningkatkan Tingkatkan pelayanana karyawan perusahan dalam melayani pelanggan.

2. Kualitas pelayanan dan kualitas area perusahan agar dapat di tingkatkan lebih baik lagi kedepannya.

\subsection{Saran}

a. Perusahan harus lebih memperhatikan tentang kepuasan pelanggan dan memberikan kualitas barang yang lebih baik lagi agar pelanggan merasa nyaman dan puas apa bila pelanggan datang ke PT Matahari epartemen StoreBlu Plaza Bekasi.

b. Perusahan seharusnya mempunyai kotak keluhan untuk pelanggan agar dapat masukkan dari pelanggan terhadap perusahaan

\section{DAFTAR PUSTAKA}

\section{Jurnal}

Yosi Yonata,Cut Fiarni,Marseli Afyuni Tania.(2016:1).Perancang Sistem Informasi Pengukur Kepuasaan Pelanggan Perusahaan Asuransi Dengan Metode Servqual,IPA Dan Analisa Regresi Liner Sederhana.Bandung : Journal Telematika

\section{Buku}

As, Rossa dan Shalahuddin, M. 2014. Rekayasa Perangkat Lunak Terstruktur dan Berorientasi Objek. Informatika. Bandung

Deden Insan Nurdiansyah.(2016:599).Sistem Pengukur Pelayanan Untuk Meningkatkan Kepuasaan Nasabah Menggunkan Metode Servqual.Yogyakarta : Seminar Intersasional Teknologi Informasi dan teknologi.

Erlina.(2011).Metode Servqual Dari Perspektif Internal Dan Eksternal.Yogyakarta : Seminar Intersasional Teknologi Informasi dan teknologi

Mohammad Imam Shalahudin. ( 2011). Sistem Pengukur Pelayanan UntukMeningkatkan Kepuasaan.Yogyakarta : Pustaka Pelajar 